\title{
Bullying in Old Age: \\ A Qualitative Study on Older Adults' \\ Perceptions About Being Bullied
}

\section{Sofia von Humboldt,' José Alberto Ribeiro-Gonçalves,' and Isabel Leal' (iD}

\begin{abstract}
Significant demographic changes and a growing aging population increasingly emphasize the importance of assessing phenomena of violence against older adults, who constitute a vulnerable population. Therefore, bullying in old age is a poorly studied phenomena, but of growing importance. This study aims to analyze the perspectives of bullying in old age, using qualitative research at a cross-national level. We interviewed 173 older participants aged 65-9I years. Participants were Portuguese and English and lived in the community. Participants were subjected to semi-structured interviews. All the interviews went through a process of content analysis. Sample recruitment occurred through initial telephone contact, followed by a request to participate. Outcomes of content analysis produced seven themes, all of them associated with bullying experiences such as compromised learning capacity, loss of sense of agency and decision-making, asexuality, less attractive appearance, less social skills, gender discrimination, and less financial resources. Portuguese older adults felt mostly bullied for their loss of sense of agency and decision-making, less attractive appearance, less social skills, and less
\end{abstract}

\footnotetext{
'ISPA—Instituto Universitário, Lisbon, Portugal
}

\section{Corresponding Author:}

Sofia von Humboldt, William James Center for Research, ISPA—Instituto Universitário, Rua Jardim do Tabaco, 34, Lisboa II49-04 I, Portugal.

Email: sofia.humboldt@gmail.com 
financial resources, while English participants mostly felt bullied for their compromised learning capacity, gender discrimination, and asexuality. The themes identified as being the most prominent in bullying are valuable guidelines for social policies and interventions toward bullying among older adults. Considering the scarcity of studies on bullying in older adults, this study is relevant for understanding the experience of older adults in relation to being bullied and for implementing psychosocial intervention programs including bullying situations that affect community-dwelling older adults.

\section{Keywords}

Bullying, cross-cultural, community-dwelling, older adults, qualitative study

\section{Introduction and Literature Review}

Rising average life expectancy and improved health and well-being resources has allowed people today to live better and longer (Mathers et al., 2015; World Health Organization [WHO], 2015). However, there are concerns about how the social implications of these population changes may underline maladaptive relational phenomena involving more vulnerable populations (Krug et al., 2002; Wolf et al., 2002), such as episodes of violence against older adults (Krug et al., 2002). Although there is little data on bullying in old age, bullying is estimated to affect between $10 \%$ and $20 \%$ of older adults (Manacchio, 2019). According to a recent study by the WHO, among 53 European countries, Portugal is one of the five countries with most violence against older adults, reporting a rate of $39 \%$ of victims being older adults, and also highlighting situations of serious abuse and bullying (WHO, 2015).

Studying the phenomena of bullying in old age is becoming increasingly important (Zsoldos et al., 2014). Although often associated with school contexts, bullying can occur in a variety of other contexts and in different age groups (McDonald et al., 2015). Bullying can be defined as the practice of violent behavior with physical, psychological, and/or social consequences, characterized mainly by three components: repeating over a significant period; intentional (not accidental); and occurring within relationships dominated by an imbalance of power (imbalance by status or force; Walsh et al., 2011).

Although bullying can often involve abuse, and both concepts imply aggression, they constitute different entities (R. P. Bonifas, 2015). In abuse, victims are usually vulnerable and dependent (e.g., functional, financial) on the offender, while in bullying both the offender and the victim are often vulnerable adults and the victim is not necessarily dependent on the offender 
(R. P. Bonifas, 2015). In older adults, bullying often occurs in social or institutional settings where differences (e.g., functional capacity) are observable (Gutman, 2012b). In the community, bullying experiences can happen in community centers or even from friends or relatives (National Center for Assisted Living [NCAL], 2017; Yon et al., 2017). In this context, bullying can take the form of stereotyped comments, offenses, and verbal aggressions, and older people practice a more adaptive and resilient approach (R. P. Bonifas, 2015; Walsh et al., 2011). Overall, the causes of bullying are complex and dependent on the age difference between victim and bully, and associated with the social and/or family dimension of both actors (MacNeil, 2002).

Violence can manifest itself in many ways, but five types are generally considered in the literature: physical, psychological, sexual, financial/material, and neglect (Naughton et al., 2010; Pillemer et al., 2016). The types of violence and their prevalence vary significantly according to the cultural and social context, and bullying events can include several types of violence (Lachs \& Pillemer, 2015; NCAL, 2017; Pillemer et al., 2016).

In general, factors contributing to bullying in older adults include gender, where women are the most abused; difficulties in functional capacity, particularly when there are difficulties in mobility and greater dependence on others; poor mental health, with indicators such as high levels of depression and anxiety; and cognitive impairments, such as memory deficits (Jeon et al., 2019; Pillemer et al., 2016; Wolf et al., 2002). In addition, a poor perceived physical appearance, in particular when there is body image disturbance, less socioemotional skills (as in mismanagement of emotions), and economic issues (such as low income) can contribute directly to the occurrence of bullying (Jeon et al., 2019; Pillemer et al., 2016; Wolf et al., 2002). Likewise, ageism is often one of the factors promoting bullying, through subjects like the myth of "asexuality" in old age and the false beliefs of older adults being "useless" and "overloading" in society (Gutman, 2012b; Krug et al., 2002).

There is a marked lack of studies on bullying in older adults (McDonald et al., 2015), particularly there is a significant terminological incoherence that influences the specific study of bullying in older adults: bullying events are often indiscriminately studied in broader investigations about abuse, violence, harassment and other concepts (Walsh et al., 2011; Yon et al., 2017). However, some studies have contributed significantly to the literature in this area (Walsh et al., 2011), such as the study by Yon et al. (2017) involving 28 countries, which found that psychological abuse was the most common form of abuse (Yon et al., 2017). Within the community context, increasingly adults work until a later age and there has also been a significant occurrence of bullying in older adults in this work context, increasing the incidence of 
psychiatric illness (Powell, 2010; Zsoldos et al., 2014). However, there seem to be more studies focused on bullying in institutionalized elderly than in community-dwelling elderly (Lapuk, 2007; McDonald et al., 2015).

Therefore, qualitative studies can be fundamental toward making a better distinction and conceptual cohesion, and allowing a closer approach to the participant and the experience of the bullying phenomenon, which is essential in such a sensitive subject in this age range (De Donder et al., 2011). Similarly, bullying is a complex issue that requires a full understanding of the social dynamics in which older adults are involved (cross-cultural approach, which is very scarce), to isolate the specific biases of monocultural studies (Walsh et al., 2011; Zsoldos et al., 2014). These studies may contribute to a greater involvement of older adults and their families in the research processes, since most studies that have been done in this area have relied on the information given by professionals (e.g., health professionals) and not with older adults themselves or their relatives, who are the closest and most direct sources of information for older adults (C. L. Erlingsson, 2007).

Bullying studies also tend to exclude older adults with cognitive or physical deficits (Pillemer et al., 2016), and research in this area would also provide the basis for developing effective strategies to prevent and respond to this type of aggression (De Donder et al., 2011; Yon et al., 2017). Furthermore, among the few studies, most focus only on bullying in older adults in continuing/institutionalized health care (Lapuk, 2007; McDonald et al., 2015). Knowledge about older adults living in the community is valuable for planning public health resources. In this context, this study aims to analyze the perspectives of a cross-cultural sample of older adults on bullying.

\section{Method}

\section{Recruitment and Sampling}

Sample recruitment occurred through initial telephone contact, followed by a request to participate in the interview. The telephone number of the participants was obtained through the institutions older adults attend (e.g., social activity centers and senior universities) and with which the researchers had previous contacts. Data sharing rules and participant consent were respected. We obtained, through a sampling by convenience, a total of 200 Portuguese and English older community-dwelling people, in the Lisbon Metropolitan area and southern regions of the country; 195 older adults agreed to participate in the study, of which 173 were included in the final study sample, yielding an unweighted response rate of $88.7 \%$ and a weighted response rate of $92.2 \%$. The remaining participants did not attend the interviews due to lack 
Table I. Sample Sociodemographic Characteristics.

\begin{tabular}{|c|c|}
\hline Characteristics & $(n=173)$ \\
\hline Age, mean $\pm S D$ & $73.5 \pm 4.4$ \\
\hline \multicolumn{2}{|l|}{ Gender, $n(\%)$} \\
\hline Women & III (64.0) \\
\hline Men & $62(36.0)$ \\
\hline \multicolumn{2}{|l|}{ Living status, $n(\%)$} \\
\hline Alone & $42(24.4)$ \\
\hline With others & $|3|(75.6)$ \\
\hline \multicolumn{2}{|l|}{ Nationality, $n(\%)$} \\
\hline English & $94(54.1)$ \\
\hline Portuguese & $79(33.9)$ \\
\hline \multicolumn{2}{|l|}{ Education $n(\%)$} \\
\hline Primary school & $66(38.2)$ \\
\hline Middle school & $44(25.4)$ \\
\hline$\geq$ High school & $63(36.4)$ \\
\hline \multicolumn{2}{|l|}{ Marital status $n(\%)$} \\
\hline Married or cohabiting & $104(60.0)$ \\
\hline Having a spouse or other intimate relationship & $69(40.0)$ \\
\hline \multicolumn{2}{|l|}{ Professional status $n(\%)$} \\
\hline Active & $45(25.8)$ \\
\hline Inactive & $128(74.2)$ \\
\hline \multicolumn{2}{|l|}{ Family annual income $n(\%)$} \\
\hline$\leq € 25,000$ & $73(42.1)$ \\
\hline$>€ 25,000$ & 100 (57.9) \\
\hline \multicolumn{2}{|l|}{ Perceived health $n(\%)$} \\
\hline Good & $107(62.1)$ \\
\hline Poor & 66 (37.9) \\
\hline
\end{tabular}

of availability. Exclusion criteria were cognitive level (above the MiniMental State Examination [MMSE] cut-off level) and being at least 65 years of age. Participants showed the following characteristics: average age of 73.5 years $(S D=4.4)$, with a range of 26 years $(\min =65$ and $\max =91)$; more than half perceived their health as good (62.1\%); a quarter were professionally active $(26 \%)$; most were married $(69 \%)$ or windowed $(15 \%)$; and approximately $75 \%$ lived with others (see Table 1 ).

To assess the indicators that led to the perception of being bullied, qualitative data were collected through in-depth semi-structured interviews according to the guidelines of Kallio et al. (2016). The interviews took place between December 2018 and December 2019 and were conducted in Portuguese and in 
English, with an average duration of approximately 40 min per interview. All interviews were conducted at the participants' homes. The interview process took place through three main steps: (a) the contents and objectives of the study were presented to each participant, (b) the participants agreed to the objectives and gave consent to participate before starting the interviews, and (c) the interview was conducted by asking questions about three main topics: perceived causes of bullying, resources activated in bullying situations, and psychological consequences of bullying experiences. In addition, the interviewers posed additional questions throughout the interview process to better understand the bullying phenomenon in these older people. All interviewers had a short guide, identical to all interviewers, with the semi-structured interview to standardize the data collection process. During this process, we ensured that the content selected and reported by the participants had sufficient meaning and negative impact to constitute an aggressive situation characterizable as bullying. Additionally, the perceived health status was measured through a single item ("How do you perceive your health status actually?"). All interviews were audio recorded and fully transcribed. For each transcribed interview, there was first an in-depth reading, with exhaustive contact with the material for further content analysis, according to Bardin's (1977) indications.

Considering the sensitivity and particularity of the topic of bullying in old age, the interviewers obtained previous training in the interviews to facilitate the sharing and expression of these experiences of abuse. All procedures were approved by the William James Center for Research Ethics Committee, Instituto Universitário (ISPA) - University Institute, and were in accordance with the ethical standards of the 1964 Helsinki Declaration and its subsequent amendments or comparable ethical standards.

\section{Data Analysis}

After reading the interview transcripts in depth, content analysis began with the division of information (Bardin, 1977; C. Erlingsson \& Brysiewicz, 2017). First, data were condensed to generate units of meaning, which convey the main message of explicit content. Next, codes were created for the units of meaning. These facilitate the link among units of meaning, even at an operational level and without much elaboration (C. Erlingsson \& Brysiewicz, 2017). The next step was to constitute a set of categories from the already constituted codes. In this process of organization, codes that referred to the same content were gathered. Category names were short and intuitive (Bardin, 1977; C. Erlingsson \& Brysiewicz, 2017). The analysis process also gave rise to themes that emerged from the joining of two or more categories, through a more reflective categorization and focus on the latent content (C. Erlingsson \& Brysiewicz, 2017). 


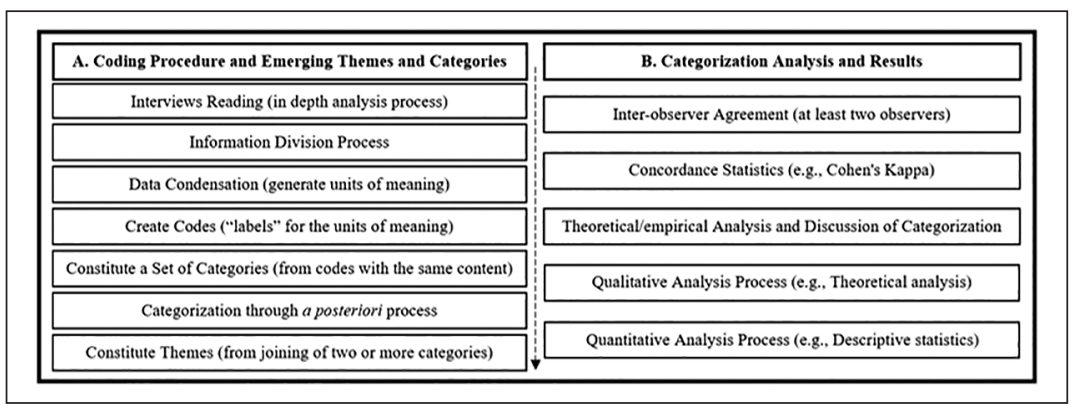

Figure I. Process of content analysis.

Categorization was applied a posteriori (bottom-up process): the category system resulted from the analogical and progressive classification of the contents themselves. The conceptual title of each category was only defined at the end of the operation (Bardin, 1977; C. Erlingsson \& Brysiewicz, 2017). Throughout the content organization procedure, the coding process followed some rules (e.g., mutually exclusive and consistently applied codes, homogeneity) to ensure the replicability and reliability of the analysis (Bardin, 1977). Finally, qualitative analysis (e.g., theoretical/empirical analysis) and quantitative analysis (e.g., descriptive statistics) were made (Bardin, 1977). Interobserver agreement was used, through at least two observers, as well as concordance statistics (e.g., Cohen's kappa) to ensure reliability (C. Erlingsson \& Brysiewicz, 2017). Cohen's kappa scores for reliability among evaluators showed a high level of agreement $(.82<\kappa<.97, p<.01)$. Furthermore, when the information provided by the participants no longer provided new knowledge, nor contributed to the richness of the analysis, the process was stopped due to theoretical saturation (Nelson, 2016). This whole procedure was synthesized in the scheme adapted according to Bardin's approach (1977; Figure 1).

\section{Results}

We analyzed seven nonmutually exclusive themes that embody the diversity of narratives articulated by participants on being bullied in old age. The themes are inclusive, unless otherwise indicated. Although participants did not always clearly use the word "bullied," their narratives indicated contexts and indicators consistent with the perception of being bullied. The substantiation of being bullied was indicated in the following seven major themes: compromised learning capacity, loss of sense of 
agency and decision-making, asexuality, less attractive appearance, less social skills, gender discrimination, and less financial resources. All names are pseudonyms. In addition, the information shared by each participant may contribute to different topics.

\section{Theme I: Compromised Learning Capacity}

Some participants $(n=143)$ indicated that as they get older, they were perceived as having lost some cognitive skills, such as the speed of learning something new. This theme was mostly reported by English older participants $\left(n_{E n g}=100 ; n_{\text {Port }}=43\right)$. Chris explained:

If I receive a smartphone as a present, people cannot expect us to understand everything at once, as it would happen with a teenager. Even if they explain it to us, it can take more time to process the information. However, we have the capacity to learn everything. In our time, there were not all these smart gadgets. (Chris; male, 72 years old)

Indeed, technology seems to be an issue in which older participants felt more bullied. Carlos indicated that

I am 69 years old and I have always liked change. Especially nowadays that technology just keeps evolving at such a high pace, I always try my best to be on par with it. But whenever I try to discuss it with my children they always laugh and claim that I am too old to get it. Even though I know they mean it in a playful manner, it always makes me feel like age has turned me into a limited person. (Carlos; male, 69 years old)

Driving was pointed out as an issue in which they felt discriminated,

I got my driver's license relatively late in life. If I recall correctly, I got myself in a conflict and a person said to me that by the time you start driving, you'll have forgotten all the road rules, old man. Do us all a favor-just stay at home and avoid being a menace to other drivers. (Jo; male, 73 years old)

Learning new abilities seems to be a focus of bullying. Maria reported that

It wasn't until I was 58 years old that I found my devotion for art. I've attended a lot of art schools for the past years. I can count on my fingers those in which professors viewed me as a normal student with less learning capacity to pass the classes. (Maria; female, 76 years old) 
Indeed, learning abilities and brain plasticity are a developmental process and continue to play a significant role in older adulthood. Cognitive and motor activities have to be intellectually stimulating and physically appropriate to bring about maximal benefits to the aging brain. Vivian reported that "I am old but I continue to do yoga because it helps relax my brain; I can get a little distracted from this stressed world. It stimulates me to be active" (Vivian; female, 77 years old).

Being perceived as slow was pointed out by some participants:

I am 67 and work as a cashier at a supermarket. A couple of days ago I was attending a lady and, seeing that I'm relatively slower than my coworkers, she eventually lost her patience and began calling me out on why I'm being so slow and that old folks should just stay at home and not interfere with the daily lives of others. Those words were remarkably hurtful. (Luisa; female, 67 years old)

\section{Theme 2: Loss of Sense of Agency and Decision-Making}

One hundred and two participants indicated that they felt bullied by their decision-making and felt that their sense of agency was being affected and linked with loss of autonomy. This theme was mostly reported by Portuguese older participants $\left(n_{\text {Port }}=89 ; n_{\text {Eng }}=13\right)$. Moreover, the biggest threat to participants' sense of agency seemed to have come from family members who make decisions on behalf of older adults and thereby disempower them. Laura indicated that "I would like them to let me make my choices as I let them make their choices" (Laura; female, 75 years old).

The diminishing ability to make decisions, either because of illness or because younger generations assume that older people are unable to make decisions is a major concern for these participants. "My daughter thinks I can't make my own decisions" (Nina; female, 74 years old).

Decision-making in old age seems to be a community issue as well, including the capacity to interact with service providers and policy makers. "I'm quite capable of making my choices and I still know what's good for me. I am used to look for my own solutions in my community" (Nina; female, 74 years old). Rudy added,

I went voting and strangely enough, there weren't many individuals my age, which left me wondering why. Then, I started having people come up to me and making rude remarks about the fact that I am too old to vote. It finally clickedthat the opinion society has about older adults: fragile, old-fashioned and ignorant people, who have no say on anything in general, and not relevant to have the slightest amount of contribution for our future. (Rudy; female, 70 years old) 
Participants indicated that they feel the loss of their role in society,

It's a fact that it is a common saying to Look up to our elders, but does it actually function like that? I feel that we continuously keep losing the relevancy of our role in society. Currently, a good portion of the youth uses us as a reference as to what not to be. I myself have had episodes in which neither my actions or opinions were taken into account because I'm old and have nothing to say. (Brian; male, 79 years old)

\section{Theme 3: Asexuality}

Ninety-seven participants indicated that they were frequently perceived as asexual because they were old. This theme was mostly reported by English older participants $\left(n_{\text {Eng }}=89 ; n_{\text {Port }}=13\right)$. Indeed, many relate old age with asexuality. Asexuality is the lack of sexual attraction to anyone, or little or no interest in human sexual activities. Sarah indicated,

It seems like others have nothing else to do. I am 73 years old and they say I do not have sexual desire. I am not a virgin; I have a sexual life and I would like others to live their sexual lives freely, instead of talking about mine. (Sarah; female, 69 years old)

\section{Oscar reported that,}

when I share my sexuality, people generally tend to devalue my emotional and physical needs, implying that I am robot that cannot feel any sort of emotion, which is very far from true. It makes connecting with others, and trusting them for that matter, very difficult. (Oscar; male, 79 years old)

Some participants added that older adults were perceived as heterosexual and that alternatives to gender orientation were not expected in old age. Moreover, some lesbian, gay, bisexual and transgender (LGBT) participants felt bullied in their gender orientation. Carl verbalized: "It can either have a sexual orientation or the lack of one. However, in my mind, I never understood why this was related to being aged" (Carl; male, 69 years old). In addition, Gus indicated that,

I identify as a 70 year-old gay man. It was never was easy to integrate myself in the society. I tried taking part in LGBT pride events and I have, as well, tried to integrate myself amongst the heterosexual community and experienced the same outcome. It is like I did not have a gender. I feel very frustrated. (Gus; male, 69 years old) 


\section{Theme 4: Less Attractive Appearance}

Participants $(n=86)$ reported that old age was frequently associated with a reduced attractive appearance and that this was affecting their current self-concept. This theme was mostly reported by Portuguese participants $\left(n_{\text {Port }}=59, n_{\text {Eng }}=30\right)$. Britney verbalized:

the fact I now have wrinkles does not mean I have been ugly my whole life. To tell you the truth, I was a model! I aged, but I am proud of my wrinkles because they represent my life experiences, and most people who offend me don't even know why. (Britney; female, 78 years old)

Some participants indicated that they were bullied for looking older. "My appearance bothers many people. The question is why? Is it because I'm old? I want to see them at their old age" (Ruth; female, 81 years old).

Appearance seemed to be important to these participants. Julie asks: "Being attractive in adolescence and adulthood is important, but why would not be important old age?" (Julie; female, 71 years old). Linda indicated that "I am missing some of my teeth, including the front ones, making it very difficult to communicate verbally. Strangers rarely take me seriously in face-toface interactions, and sometimes even laugh at me" (Linda; female, 69 years old). Bill added that "my hair started thinning at around sixty-one years of age, so I decided to shave it all off. From that moment up until now, I've been told that I have an old crystal ball head countless times by others" (Bill; male, 89 years old).

\section{Theme 5: Less Social Skills}

Participants $(n=74)$ pointed out that they were frequently bullied because they were not good with their social relations. This theme was mostly reported by Portuguese participants $\left(n_{\text {Port }}=43, n_{\text {Eng }}=31\right)$. Indeed, social skills are important in old age, since these help to avoid loneliness and depression. Dina believes that, "it is important to have friends, but in old age, we have a few old friends and we don't need more" (Dina; female, 76 years old).

Some participants highlighted that they are focused on good and rewarding relationships: "Having a lot of friends is not exactly my goal. My goal at this age is to have meaningful relationships" (Francis; female, 72 years old).

Other participants feel frustrated and impotent with being bullied about their social skills: 
I am almost one-hundred percent sure I have depression due to not being able to convey my emotional needs to the outer world - so I just bottle it all up. And I can't express myself because I am depressed, which creates this endless cycle that then leads to self-loathing crises. I have tried breaking out of it but, the fact that society tells you that this is mainly a phase of growing old, certainly does not help. (Gabriela; female, 71 years old)

\section{Theme 6: Gender Discrimination}

Participants ( $n=68$ ) expressed having felt gender discriminated sometime in their older adult life. This theme was mostly reported by English participants $\left(n_{\text {Eng }}=43 ; n_{\text {Port }}=25\right)$. In particular, older women indicated having felt gender discrimination in old age. In situations involving migrant older adults, women can often be excluded compared with men. Maria reported "Being left out is a horrible feeling, it makes us think we are worthless ... just because we are different" (Maria; female, 67 years old).

Gender discrimination was also felt by male participants: Carl verbalized "No one is safe! Men, can also be victims. I've already felt discriminated while in line in the supermarket!" (Carl; male, 68 years old). Roger added: "I am an old man who has been sexually assaulted. Although I've tried countless times, my attempts at seeking psychological help have not been taken seriously solely because I am a man." (Roger; male, 83 years old).

Sonia reported that,

I am 70 and have been an overweight female for the most part of my life because of medical conditions. I have always gotten unwanted attention, yet I feel as if the situation has significantly aggravated ever since age started playing an important role in the equation. (Sonia; female, 70 years old)

Gender abuse was felt by some participants 'I'm constantly being taken advantage of by my husband. He is verbally violent with me and forces himself on me without my consent" Anna reported (Anna; female, 69 years old).

\section{Theme 7: Less Financial Resources}

Financial abuse is very similar to other forms of abuse of the elderly, in that it can be devastating to the victim and is often attributed to family members, trusted friends and caregivers. Fifty-five participants reported being bullied for financial reasons. This theme was mostly reported by Portuguese participants $\left(n_{\text {Port }}=31 ; n_{\text {Eng }}=24\right)$. "I never thought I'd reach this point, reach this age and feel so poor" (Hugo; male, 66 years old). John added that, 
my retirement plan is not enough to guarantee me a somewhat decent life, so, every now and then, I see myself having to go out in the streets and ask people for money. It is, undoubtedly, something I truly wish I did not have to do because I'm judged and discriminated by, probably, ninety percent of people whom I ask for money. (Daniel; male, 69 years old)

Moreover, Sophia indicated that,

because healthcare costs increase with age, to be able to afford it, I am obligated to cut down on other necessities, one good example being food. This causes problems for my nutrition, giving me a malnourished look that I have to carry and that has been a subject of mockery many times. (Sophia; female, 68 years old)

However, some older adults, despite frequently indicating low income, are more financially satisfied than younger adults. "I don't have much, but it's enough for me" (Bea; female, 65 years old).

Participants pointed out their loss of financial capacity and associated loss of social relationships:

I always did my best to spoil my children when they were younger. Now adults, they expect the same, though my financial resources don't allow it. It seems that they cannot place themselves in my shoes. In fact, they have become more and more distant ever since the day I said I would not be able to support them anymore. It truly breaks my heart. (Grant; male, 71 years old)

\section{Discussion}

Outcomes indicate that participants draw upon the following seven nonmutually exclusive themes related to older adult perspectives on bullying in old age: compromised learning capacity, loss of sense of agency and decisionmaking, asexuality, less attractive appearance, less social skills, gender discrimination, and less financial resources.

The data analysis intended to fill a knowledge gap about older adult perceptions of being bullied and to elaborate an interpretative framework for the bullying construct. Results illustrate that older adults perceived this construct in diverse and rich manners.

Compromised learning capacity was the most frequent theme indicated by these participants. In old age, cognitive function may be slower or impaired, inducing lower learning and information apprehension skills, posing a risk for bullying, violence, or abuse (Faustino et al., 2016; McCausland et al., 2016). Some studies indicate that when older people 
are less able to learn, they are more vulnerable to abuse, which can configure bullying situations, particularly sexual violence and neglect (Faustino et al., 2016).

Similarly, older adults with cognitive impairment are more likely to be abused by caregivers and family members (M. Lee, 2009). Indeed, one of the main risk factors for abuse in older adults is the occurrence of dementia (McCausland et al., 2016; Sethi et al., 2011). In addition, lower levels of episodic memory, perceptual speed and overall cognition also appear to be associated with an increased risk of abuse (X. Dong et al., 2011). One of the main risk factors for elder abuse is difficulties in assimilating, processing and transforming information; and decreased abilities, such as attention, perception, and language processing, which make them more vulnerable (J. Y. Lee, 2015; Pauwels et al., 2018). Similarly, lower levels of cognitive function appear to be associated with a higher likelihood of being a victim of fraud (James et al., 2014). Annually millions of older people are estimated to be victims of fraud and sometimes in a repeated way, which can configure bullying situations. Some authors attribute this high incidence to declines in cognitive functioning, particularly failure of decision-making processes, which are essential for recognizing, preventing and responding to this type of abuse (Han et al., 2016; James et al., 2014; Shao et al., 2019). Complex and higher order cognitive functions can significantly decrease in older adults, so level of cognitive difficulty also seems to be directly related to prevalence and factors involved in older adult abuse by family members and caregivers (Kishimoto et al., 2013; Pauwels et al., 2018). Also, caregiver sex (male), emotional burden and the nature of the neuropsychiatric symptoms of older adults seem to influence the indicators of psychological and physical maltreatment, but variables such as the older adult's gender did not show a significant effect on indicators of maltreatment (Kishimoto et al., 2013).

The loss of sense of agency and decision-making was the second most indicated theme related to perception of being bullied. According to Goll et al. (2015), among the greatest fears of older adults are feelings of disability, dependence, uselessness and loss of social roles they once had, which are often accentuated in situations of bullying and discrimination. Loss of sense of agency, together with situations of infantilization (e.g., care homes) and underestimation of their real abilities can configure situations of abuse, which undermine their decision-making and have a direct impact on older adult well-being (Marson \& Powell, 2014). Likewise, increasing prejudice and bullying often occurs with loss of sense of agency and decision-making among older adults, in a stereotypical and inappropriate way through withdrawal of functions (e.g., financial decisions, driving), thus significantly affecting their self-concept and self-esteem (Goll et al., 2015). Some authors 
point out that to prevent bullying, which can lead to discrimination, individual-centered empowerment strategies may be adopted that take into account the goals, aspirations, and desires of older people (Goll et al., 2015; McWilliam et al., 1994).

Being perceived as asexual was a relevant source of bullying for older adults. The stereotype of the older adult as asexual is associated with the prevalence (until the 1960s) of the "reproductive" model of sexuality, in which nonreproductive sexuality, as in old age, is marginalized (Træen et al., 2016). Likewise, discrimination and bullying may also be associated with youth-oriented conceptions of sexuality, where sex is seen as a younger adult privilege (Hurd, 2000; Træen et al., 2016).

Furthermore, stereotyped comments and offenses are a frequent type of bullying, with a significant negative effect on the lives of older adults, when these do not possess sufficient levels of resilience to manage aggressive bullying situations (R. P. Bonifas, 2015; Walsh et al., 2011). In addition, sexual minorities among older adults are further affected by stigmatization due to their sexual orientation (R. P. Bonifas, 2015). Similarly, the higher prevalence of chronic illness and other health problems impacting the sexual function of older people may falsely reinforce the social stereotypes of "asexuality" (Heidari, 2016; Træen et al., 2016). However, there are older adult groups who consider themselves to be effectively asexual and who seem to evidence marked risk factors for erectile dysfunction (e.g., diabetes, hypertension). They also indicate that among the reasons for "asexual" status are stressprobably associated with phenomena of discrimination, stigmatization or abuse - and severe fatigue, such as erectile difficulty, nonconcern about sexuality and masturbation (Huang et al., 2014).

Aging is accompanied by changes in body weight and shape that can negatively influence older people's self-perception and make them more vulnerable to various forms of abuse and bullying (Træen et al., 2016). Weight stigmatization is common in several studies including older adults and seems to be associated with depressive symptomology, general psychiatric symptoms and decreased self-esteem (Træen et al., 2016). Studies show that stigmatization and bullying in particular have a significant impact, because the causes of body changes are often attributed to the individual's self-control (Jeffries et al., 2018; NCAL, 2017). In particular, women report a fear of getting old, associated with the social consequences of losing their youthful body, which may be a source of discrimination and bullying (Hurd, 2000; NCAL, 2017).

Bullying can be felt through decreased social skills. Some studies indicate that older people with low social fulfillment have a significant tendency to connect with others, including strangers, making occurrences of abuse and 
bullying easier (Lichtenberg et al., 2013, 2016). Older people with psychological vulnerability - defined by the authors as a combination of depressive symptoms and poor fulfillment of social needs-were 3 times more likely to be victims of fraud (Lichtenberg et al., 2013; Shao et al., 2019). On the contrary, these difficulties with social context can sometimes manifest themselves in social isolation, increasing the likelihood of abuse due to greater exposure to being misled by others, feelings of loneliness and a weaker support network (X. Q. Dong, 2015; Shao et al., 2019). However, if the older adult caregiver lives in the same house, the risk of abuse is also increased, associated with the high probability of relational problems and emotional overload (Wolf et al., 2002). Moreover, worldwide, social support has been found to significantly reduce the risk of abuse (Pillemer et al., 2016).

Gender discrimination was felt by these older adults in both genders, however $64 \%$ of the participants who pointed out this theme were women. Much of the literature suggests that women tend to be more bullied than men (Gil et al., 2015; Jeon et al., 2019), particularly financial and emotional bullying (Pillemer et al., 2016). A recent meta-analysis confirms this trend in Asian, Mediterranean, and European countries, although not in the American continent, where men seem to be the most abused (Yon et al., 2017).

Similarly, sexual minorities are victims of bullying (R. P. Bonifas, 2015). Although little is known about the percentage of LGBT seniors who are bullied, data on the victimization of this population are high. When asked, $82 \%$ of LGBT seniors report having suffered bullying behavior (e.g., physical or verbal attack and threat, property damage) at least once and 64\% report various bullying behaviors (R. P. Bonifas, 2015).

Finally, participants highlighted being bullied because of lower financial resources. Several studies associate low socioeconomic status with situations of abuse, discrimination and bullying (Naughton et al., 2010; NCAL, 2017; Peterson et al., 2014). Economically more vulnerable groups tend to be more abused during old age and throughout their lives (Peterson et al., 2014). Moreover, bullying and maltreatment can be important tools for theft, fraud, and misuse of power (Rabiner et al., 2004). Particularly, when the perpetrator of abuse is a family member, older people tend not to report the situation, in addition to more passively accepting financial abuse (Kalayci et al., 2016). Specifically, in the domestic context, the prevalence of financial abuse appears to be higher than in institutional contexts, and perpetrators of abuse tend to be mostly family members rather than other caregivers (Hafemeister, 2003; Lachs \& Pillemer, 1995, 2015). In several Asian countries, lower monthly household income may contribute to a threefold increase in likelihood of older adult bullying and abuse. These results are similar to those found in other continents (Lachs et al., 1997; Yan et al., 2014). 
The present study has a number of limitations. Although this study is cross-national, we only included participants from developed countries. The sample is also not representative of the entire population and only reveals the perceptions of these participants. Sampling was performed purposefully, with the objective of facilitating the understanding of bullying in old age. Furthermore, interviews were conducted sought to be bias free, hence one core area to be addressed was predefined. Because interviews tended to be steered to this area, results could have been biased.

Notwithstanding these limitations, a major strength of this study is that all participants were community-dwelling. Many studies on bullying in older adults are related to so-called "resident-to-resident bullying," and neglect the study of this type of aggression in community-dwelling older adults (Ferrah et al., 2015; Ferreira et al., 2018). Similarly, most studies obtained their results based on reports from the teams working with older adults and some biases associated with these informants have been underlined (Ferreira et al., 2018).

Another strength is that, considering that bullying is a sensitive theme for research participation, our participants shared their experiences about this subject, Moreover, physical and cognitive limitations resulting from aging tend to decrease the nonresponse rates in the studies, which may lead to underestimate the actual occurrence of aggression (De Donder et al., 2011; Lensvelt-Mulders, 2008). Still, some studies indicate the stigma of bullying among older adults as a major limitation. Hence, research should address these acts of aggression in a comprehensive and integrative manner, understanding that bullying can be the product of older adults expressing frustration regarding unmet needs (Ferrah et al., 2015; Lachs \& Pillemer, 2015).

In this study, there was an evident cultural diversity. Portuguese older adults were mostly bullied for their loss of sense of agency and decisionmaking, less attractive appearance, fewer social skills and financial resources, while English participants felt bullied mostly for their compromised learning capacity, gender discrimination and asexuality. In-depth cross-cultural studies are essential to form the basis for further measures (De Donder et al., 2011). Similarly, studies are fundamental to identify and distinguish bullying behaviors, as well as to establish guidelines for managing such situations (Krug et al., 2002; Mathers et al., 2015). With the accentuated and progressive aging of the population, in the near future research may be an important resource for families, health professionals and older adults themselves in managing situations of aggression (R. P. Bonifas, 2015; Krug et al., 2002; WHO, 2015). Likewise, there are variables that significantly influence the daily lives of older community-dwellers, such as loneliness, social isolation 
and weak social networks, which favor the emergence of bullying (Krug et al., 2002; McDonald et al., 2015). Because these variables are directly associated with bullying, further studies can allow these variables to be better assessed and addressed (McDonald et al., 2015).

Similarly, future studies on the prevalence of bullying among older adults would be a significant contribution, as there is a scarcity of data (NCAL, 2017). In addition, studies on bullying among older adults will enable the establishment of health policies that improve the prevention of this type of aggression (NCAL, 2017; Pillemer et al., 2016), and may also inform the legislation for better and more appropriate action measures in cases of bullying (Pillemer et al., 2016). Regarding these policies, there is a scarcity of guidelines that address bullying prevention or intervention among older adults (Walsh et al., 2011; Zsoldos et al., 2014). The theoretical inconsistency and the bias toward assessing bullying almost exclusively in the school context, and in childhood, emphasize the need for practical actions in older adulthood (R. P. Bonifas, 2015). However, some evidences (e.g., R. Bonifas \& Frankel, 2012; Gutman, 2012a), and the NCAL (2017), have suggested some guidelines for preventing and addressing situations of bullying among older adults, which include committing organizations that care for older adults to comply with the principles of respect and equality; assessing risks and severity of bullying; implementing policies of zero tolerance for bullying; implementing discussions about bullying with the community, professionals, and families; creating community partnerships; developing inclusive informational materials targeted at potential victims and perpetrators; implementing strategies to support and empower victims to better manage bullying situations (e.g., assertiveness training); implementing strategies that support and enable aggressors to manage their control needs in a more adaptive way (e.g., self-control training). In addition, and based on the evidence found in this article, we suggest adding communication strategies for older adults when bullied, developing specific training programs for health professionals; developing strategies for early and comprehensive awareness of bullying in old age; and creating anonymous and confidential helplines aimed at aggressors and elderly victims of bullying.

In brief, in-depth future research is fundamental for the design of psychosocial intervention programs in the management of the above bullying situations in old age, particularly in community-dwelling older adults (Jeon et al., 2019; Powell, 2010).

\section{Authors' Note}

The authors alone are responsible for the content and writing of the paper. 


\section{Declaration of Conflicting Interests}

The author(s) declared no potential conflicts of interest with respect to the research, authorship, and/or publication of this article.

\section{Funding}

The author(s) disclosed receipt of the following financial support for the research, authorship, and/or publication of this article: We kindly acknowledge the Portuguese Foundation for Science and Technology (FCT) for the grant (Grant number SFRH/ BPD/116114/2016) which supported this research. The fund approved the design and aims of the study but did not play any role in the collecting of data, interpretation of results, or preparation of this article.

\section{ORCID iDs}

Sofia von Humboldt iD https://orcid.org/0000-0001-9664-6735

José Alberto Ribeiro-Gonçalves (iD https://orcid.org/0000-0003-4983-4770

Isabel Leal (iD https://orcid.org/0000-0002-1672-7912

\section{References}

Bardin, L. (1977). Análise de conteúdo [Content analysis]. Edições 70.

Bonifas, R., \& Frankel, M. (2012). Senior bullying, Part 4: Potential interventions to reduce bullying. My Better Nursing Home. http://www.mybetternursinghome. $\mathrm{com}$ /senior-bullying-part-4-potential-organizational-level-interventions-toreduce-bullying/

Bonifas, R. P. (2015). The prevalence of elder bullying and impact on LGBT elders. In D. A. Harley \& P. B. Teaster (Eds.), Handbook of LGBT elders (pp. 359-372). Springer.

De Donder, L., Luoma, M.-L., Penhale, B., Lang, G., Santos, A. J., Tamutiene, I., . . . Verté, D. (2011). European map of prevalence rates of elder abuse and its impact for future research. European Journal of Ageing, 8, 129-143. https://doi. org/10.1007/s10433-011-0187-3

Dong, X., Simon, M., Rajan, K., \& Evans, D. A. (2011). Association of cognitive function and risk for elder abuse in a community-dwelling population. Dementia and Geriatric Cognitive Disorders, 32, 209-215. https://doi.org/10.1159/000334047

Dong, X. Q. (2015). Elder abuse: Systematic review and implications for practice. Journal of the American Geriatrics Society, 63, 1214-1238. https://doi. org/10.1111/jgs.13454

Erlingsson, C., \& Brysiewicz, P. (2017). A hands-on guide to doing content analysis. African Journal of Emergency Medicine, 7, 93-99. https://doi.org/10.1016/j. afjem.2017.08.001

Erlingsson, C. L. (2007). Searching for elder abuse: A systematic review of database citations. Journal of Elder Abuse \& Neglect, 19, 59-78. https://doi.org/10.1300/ j084v19n03_04 
Faustino, A. M., Moura, L. B. A., \& Gandolfi, L. (2016). Relationship between violence and cognitive function in the elderly. Journal of Nursing, 10, 1717-1723. https://doi.org/10.5205/1981-8963-v10i5a13547p1717-1723-2016

Ferrah, N., Murphy, B. J., Ibrahim, J. E., Bugeja, L. C., Winbolt, M., LoGiudice, D., ... Ranson, D. L. (2015). Resident-to-resident physical aggression leading to injury in nursing homes: A systematic review. Age and Ageing, 44, 356-364. https://doi.org/10.1093/ageing/afv004

Ferreira, J., Tavares, J., \& Sousa, L. (2018). Resident-to-resident elder mistreatment (R-REM): A study in residential structures for elderly people (ERI) in Portugal. Journal of Elder Abuse \& Neglect, 31, 66-76. https://doi.org/10.1080/0894656 6.2018 .1539690

Gil, A. P., Kislaya, I., Santos, A. J., Nunes, B., Nicolau, R., \& Fernandes, A. A. (2015). Elder abuse in Portugal: Findings from the first national prevalence study. Journal of Elder Abuse \& Neglect, 27, 174-195. https://doi.org/10.1080 /08946566.2014.953659

Goll, J. C., Charlesworth, G., Scior, K., \& Stott, J. (2015). Barriers to social participation among lonely older adults: The influence of social fears and identity. PLOS ONE, 10, 1-17. https://doi.org/10.1371/journal.pone.0116664

Gutman, G. M. (2012a, June). Older adult bullying: Psychological abuse by a different name? Communication presented at Bullying Prevention Strategy Think Tank, Edmonton, Canada.

Gutman, G. M. (2012b, June). Senior-to-senior bullying: What do we know about it? How is it being dealt with? [Conference session]. Communication presented at the International Network for the Prevention of Elder Abuse, 8th World Conference, Seoul, Korea.

Hafemeister, T. L. (2003). Financial abuse of the elderly in domestic setting. In R. J. Bonnie \& R. B. Wallace (Eds.), Elder mistreatment: Abuse, neglect, and exploitation in an aging America (pp. 382-445). National Academies Press.

Han, S. D., Boyle, P. A., James, B. D., Yu, L., \& Bennett, D. A. (2016). Mild cognitive impairment and susceptibility to scams in old age. Journal of Alzheimer's Disease, 49, 845-851. https://doi.org/10.3233/JAD-150442

Heidari, S. (2016). Sexuality and older people: A neglected issue. Reproductive Health Matters, 24, 1-5. https://doi.org/10.1016/j.rhm.2016.11.011

Huang, Y. P., Chen, B., Ping, P., Wang, H.-X., Hu, K., Yang, H., . . Huang, Y.-R. (2014). Asexuality development among middle aged and older men. PLOS ONE, 9, Article e92794. https://doi.org/10.1371/journal.pone.0092794

Hurd, L. C. (2000). Older women's body image and embodied experience: An exploration. Journal of Women \& Aging, 12, 77-97. https://doi.org/10.1300/ J074v12n03_06

James, B. D., Boyle, P. A., \& Bennett, D. A. (2014). Correlates of susceptibility to scams in older adults without dementia. Journal of Elder Abuse \& Neglect, 26, 107-122. https://doi.org/10.1080/08946566.2013.821809

Jeffries, H., Slovak, K., \& Huston, S. (2018). Measuring and addressing elderly bullying in a senior residential community. The Journal of Sociology \& Social Welfare, 45, 30-39. 
Jeon, G.-S., Cho, S.-I., Choi, K., \& Jang, K.-S. (2019). Gender differences in the prevalence and correlates of elder abuse in a community-dwelling older population in Korea. International Journal of Environmental Research and Public Health, 16, 100-113. https://doi.org/10.3390/ijerph16010100

Kalayci, I., Yazici, S. O., Özkul, M., \& Küpeli, A. (2016). Perceptions of the elderly on elderly abuse. Turkish Journal of Geriatrics, 19, 232-237.

Kallio, H., Pietila, A.-M., Johnson, M., \& Kangasniemi, M. (2016). Systematic methodological review: Developing a framework for a qualitative semi-structured interview guide. Journal of Advancing Nursing, 72, 2954-2965. https://doi. org/10.1111/jan.13031

Kishimoto, Y., Terada, S., Takeda, N., Oshima, E., Honda, H., Yoshida, H., .. . Uchitomi, Y. (2013). Abuse of people with cognitive impairment by family caregivers in Japan (a cross-sectional study). Psychiatry Research, 209, 699-704. https://doi.org/10.1016/j.psychres.2013.01.025

Krug, E. G., Mercy, J. A., Dahlberg, L. L., \& Zwi, A. B. (2002). The world report on violence and health. The Lancet, 360, 1083-1088. https://doi.org/10.1016/ s01406736(02)11133-0

Lachs, M. S., \& Pillemer, K. (1995). Abuse and neglect of elderly persons. New England Journal of Medicine, 332, 437-443. https://doi.org/10.1056/ nejm199502163320706

Lachs, M. S., \& Pillemer, K. A. (2015). Elder abuse. New England Journal of Medicine, 373, 1947-1956. https://doi.org/10.1056/nejmra1404688

Lachs, M. S., Williams, C., O’Brien, S., Hurst, L., \& Horwitz, R. (1997). Risk factors for reported elder abuse and neglect: A nine-year observational cohort study. The Gerontologist, 37, 469-474. https://doi.org/10.1093/ geront/37.4.469

Lapuk, D. S. (2007). Resident aggression in a long-term care setting: Concerns and meanings from perspectives of other residents [Unpublished doctoral dissertation]. The University of Manitoba.

Lee, J. Y. (2015). Aging and speech understanding. Journal of Audiology and Otology, 19, 7-13. https://doi.org/10.7874/jao.2015.19.1.7

Lee, M. (2009). A path analysis on elder abuse by family caregivers: Applying the ABCX model. Journal of Family Violence, 24, Article 1. https://doi.org/10.1007/ s10896-008-9192-5

Lensvelt-Mulders, G. (2008). Surveying sensitive topics. In E. D. de Leeuw, J. J. Hox, \& D. A. Dillman (Eds.), International handbook of survey methodology (pp. 461-478). Lawrence Erlbaum.

Lichtenberg, P. A., Stickney, L., \& Paulson, D. (2013). Is psychological vulnerability related to the experience of fraud in older adults? Clinical Gerontologist, 36, 132-146. https://doi.org/10.1080/07317115.2012.749323

Lichtenberg, P. A., Sugarman, M. A., Paulson, D., Ficker, L. J., \& Rahman-Filipiak, A. (2016). Psychological and functional vulnerability predicts fraud cases in older adults: Results of a longitudinal study. Clinical Gerontologist, 39, 48-63. https://doi.org/10.1080/07317115.2015.1101632 
MacNeil, G. (2002). School bullying: An overview. In L. A. Rapp-Paglicci, A. R. Roberts, \& J. S. Wodarski (Eds.), Handbook of violence (pp. 247-261). John Wiley.

Manacchio, S. (2019). Senior bullying is more common than you think. Caring Connections of New Jersey and Pennsylvania.

Marson, S. M., \& Powell, R. M. (2014). Goffman and the infantilization of elderly persons: A theory in development. The Journal of Sociology \& Social Welfare, 41, 143-158.

Mathers, C. D., Stevens, G. A., Boerma, T., White, R. A., \& Tobias, M. I. (2015). Causes of international increases in older age life expectancy. The Lancet, 385 , 540-548. https://doi.org/10.1016/s0140-6736(14)60569-9

McCausland, B., Knight, L., Page, L., \& Trevillion, K. (2016). A systematic review of the prevalence and odds of domestic abuse victimization among people with dementia. International Review of Psychiatry, 28, 475-484. https://doi.org/10.10 80/09540261.2016.1215296

McDonald, L., Sheppard, C., Hitzig, S. L., Spalter, T., Mathur, A., \& Mukhi, J. S. (2015). Resident-to-resident abuse: A scoping review. Canadian Journal on Aging, 34, 215-236. https://doi.org/10.1017/s0714980815000094

McWilliam, C. L., Brown, J. B., Carmichael, J. L., \& Lehman, J. M. (1994). A new perspective on threatened autonomy in elderly persons: The disempowering process. Social Science \& Medicine, 38, 327-338. https://doi.org/10.1016/02779536(94)90402-2

National Center for Assisted Living. (2017). Bullying among seniors.

Naughton, C., Drennan, J., Lyons, I., Lafferty, A., Treacy, M., Phelan, A., . . . Delaney, L. (2010). Abuse and neglect of older people in Ireland [Report on the National Study of Elder Abuse and Neglect]. National Centre for the Protection of Older People.

Nelson, J. (2016). Using conceptual depth criteria: Addressing the challenge of reaching saturation in qualitative research. Qualitative Research, 17, 554-570. https:// doi.org/10.1177/1468794116679873

Pauwels, L., Chalavi, S., \& Swinnen, S. P. (2018). Aging and brain plasticity. Aging, 10, 1789-1790. https://doi.org/10.18632/aging.101514

Peterson, J. C., Burnes, D. P., Caccamise, P. L., Mason, A., Henderson, C. R., Jr., Wells, M. T., . . . Lachs, M. S. (2014). Financial exploitation of older adults: A population-based prevalence study. Journal of General Internal Medicine, 29, 1615-1623. https://doi.org/10.1007/s11606-014-2946-2

Pillemer, K., Burnes, D., Riffin, C., \& Lachs, M. S. (2016). Elder abuse: Global situation, risk factors, and prevention strategies. The Gerontologist, 56, S194-S205. https://doi.org/10.1093/geront/gnw004

Powell, M. (2010). Ageism and abuse in the workplace: A new frontier. Journal of Gerontological Social Work, 53, 654-658. https://doi.org/10.1080/01634372.20 10.508510

Rabiner, D. J., Brown, D., \& O'Keeffe, J. (2004). Financial exploitation of older persons: Policy issues and recommendations for addressing them. Journal of Elder Abuse \& Neglect, 16, 65-84. https://doi.org/10.1300/j084v16n01_04 
Sethi, D., Wood, S., Mitis, F., Bellis, M., Penhale, B., Marmolejo, I. I., \& Kärki, F. U. (2011). European report on preventing elder maltreatment. World Health Organization.

Shao, J., Zhang, Q., Ren, Y., Li, X., \& Lin, T. (2019). Why are older adults victims of fraud? Current knowledge and prospects regarding older adults' vulnerability to fraud. Journal of Elder Abuse \& Neglect, 31, 225-243. https://doi.org/10.108 0/08946566.2019.1625842

Træen, B., Carvalheira, A., Kvalem, I. L., Štulhofer, A., Janssen, E., Graham, C. A., . . . Enzlin, P. (2016). Sexuality in older adults $(65+)$ - An overview of the recent literature, Part 2: Body image and sexual satisfaction. International Journal of Sexual Health, 29, 11-21. https://doi.org/10.1080/19317611.2016.1227012

Walsh, C. A., Daoust, G., \& Beamer, K. (2011). Elder abuse and bullying: Exploring theoretical and empirical connections. In C. P. Monks \& I. Coyne (Eds.), Bullying in different contexts (pp. 185-210). Cambridge University Press.

Wolf, R., Daichman, L., \& Bennett, G. (2002). Abuse of the Elderly. In E. G. Krug, L. L. Dahlberg, J. A. Mercy, A. B. Zwi, \& R. Lozano (Eds.), World report on violence and health (pp. 123-143). World Health Organization.

World Health Organization. (2015). World report on ageing and health.

Yan, E., Chan, K.-L., \& Tiwari, A. (2014). A systematic review of prevalence and risk factors for elder abuse in Asia. Trauma, Violence, \& Abuse, 16, 199-219. https:// doi.org/10.1177/1524838014555033

Yon, Y., Mikton, C. R., Gassoumis, Z. D., \& Wilber, K. H. (2017). Elder abuse prevalence in community settings: A systematic review and meta-analysis. The Lancet Global Health, 5, 147-156. https://doi.org/10.1016/s2214109x(17)30006-2

Zsoldos, E., Mahmood, A., \& Ebmeier, K. P. (2014). Occupational stress, bullying and resilience in old age. Maturitas, 78, 86-90. https://doi.org/10.1016/j.maturitas.2014.04.006

\section{Author Biographies}

Sofia von Humboldt has $\mathrm{PhD}$ in psychology from ISPA-Instituto Universitário. She is a researcher and invited professor and undergoing a postdoctoral at William James Center for Research, ISPA-Instituto Universitário and at the University of Alberta, She has a long-standing experience with older adults. Her research interests include bullying in old age, sexual well-being, adjustment to aging and mental health. Deeply committed to working with older adults, she has published 45 scientific papers, and is editor, author, and coauthor of chapters and books focused on aging and old age.

José Alberto Ribeiro-Gonçalves has a degree in psychological sciences from the University of Madeira (UMa) and a master in clinical psychology from ISPAInstituto Universitário. He started his clinical activity in the area of pediatric psychology in hospital context (Hospital de Santa Maria). Subsequently, he completed a professional internship at the Portuguese Order of Psychologists (OPP) in the field of geriatric psychiatry (Hospital Júlio de Matos). He is doctoral candidate in the 
specialty of clinical psychology at ISPA-Instituto Universitário and member of the William James Center for Research, where he develops his research in the field of aging and sexuality.

Isabel Leal has PhD in psychology (1991) from the Catholic University of Louvain (Belgium). She is full professor of ISPA - Instituto Universitário (Lisbon, Portugal), head of the Department of Clinical and Health Psychology and researcher of the William James Center for Research, I\&D. His research interests focus on the interface of health and psychology, in particular on sexual and reproductive health and on the issues of adaptation in life cycle among them the aging and the disease. She has published 250 articles in specialized journals and is the author, coauthor and editor of 50 books. 